\title{
Elbow fracture in a child
}
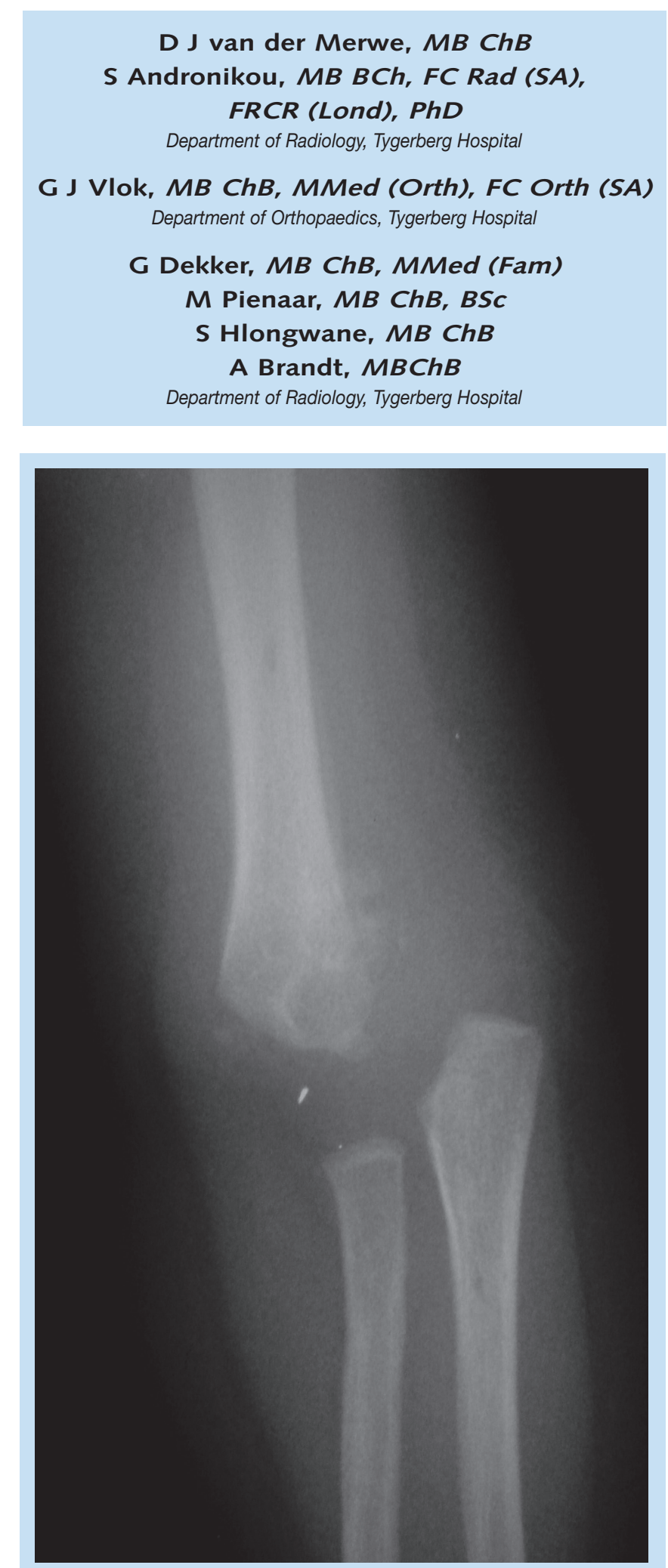

Fig. 1. Plain film of the elbow demonstrates malalignment of the distal humeral metaphysis with the proximal radial and ulnar metaphyses. The unossified epiphyses are not visible.
We present a case of a 2-year-old child who fell and injured his elbow. Plain films were taken and had the appearance of an elbow dislocation (Fig. 1). Subsequent MRI confirmed a Salter Harris I fracture of the distal humeral epiphysis (Figs 2a \& b).

\section{Discussion}

Pure dislocation of the elbow is uncommon. It involves a disarticulation of the radial head from the capitellum and the semi-lunar notch of the olecranon from the trochlea. ${ }^{1}$ In this instance, the child's radius head and proximal ulna are displaced as a unit with the distal cartilagenous humerus. This is obvious on MRI (especially GE sequence) because it demonstrates the cartilagenous components which are not visible on plain radiograph.

Separation of the entire distal humeral epiphysis is classified into three groups based on the age of the child and the degree of ossification of the lateral condyle: ${ }^{2}$

- Group A includes infants whose lateral condyle ossification centre has not appeared.

- Group B cases are between ages 1 and 3 years when the ossification centre is present (our patient).

- Group C includes older children and produces a metaphyseal fragment.

The distal epiphysis is usually displaced posteromedially. ${ }^{3}$

Diagnosis of this type of fracture can be challenging. X-rays are usually taken of both elbows but further imaging is usually needed. Modalities that have been used are ultrasound ${ }^{4}$ and arthrography. Although they help to make the diagnosis, ultrasound is operatordependent and not consistently accurate. Arthrography is associated with the risks of an invasive procedure.

MRI, as demonstrated in this patient, is an excellent modality to obtain the diagnosis of separation of the distal humeral epiphysis and avoid misdiagnosis of dislocated elbow when the elbow epiphyses are largely unossified.

1. Rasool MN. Elbow dislocation with lateral condyle fracture in children. SA Orthopaedic Journal 2006; Aug: 72-78.

2. Campbell WC. Fractures and dislocations in children. In: Crenshaw AH, ed. Campbell's Operative Orthopedics. St Louis: Mosby, 1987: 1885-1886.

3. Ruo GY. Radiographic diagnosis of fracture-separation of the entire distal humeral epiphysis. Clin Radiol 1987; 38: 635-637.

4. Dias JJ, Lamont AC, Jones JM. Ultrasonic diagnosis of neonatal separation of the distal humeral epiphysis. J Bone Joint Surg Br 1988; 70: 825-828 


\section{CASE REPORT}

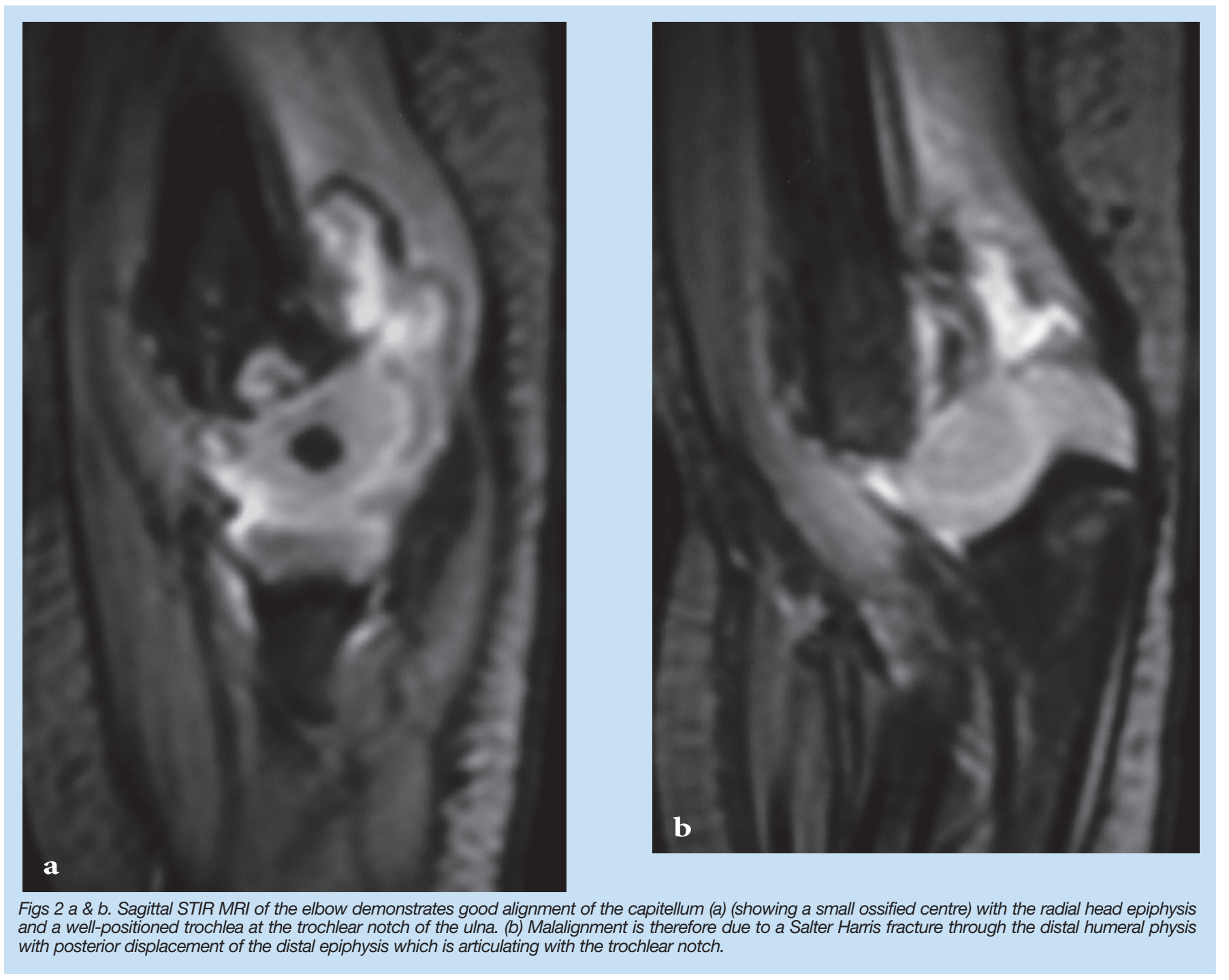

$\oplus$ 